\title{
Telework adoption and formalisation in organisations from a knowlegde transfer perspective
}

\author{
Pascale Peters* \\ Department of Business Administration, \\ Radboud University Nijmegen, \\ P.O. Box 9108, \\ 6500 HK Nijmegen, Netherlands \\ Email: p.peters@fm.ru.nl \\ *Corresponding author
}

\section{Ronald Batenburg}

NIVEL,

Postbus 1568, 3500 BN Utrecht, Netherlands

Email: r.batenburg@nivel.nl

\begin{abstract}
This study uses a knowledge transfer perspective, focusing both on 'disruptive' and 'commiting' consequences of teleworking affecting organisational knowledge transfer, to understand variations in the adoption and formalisation of teleworking practices in organisations. It hypothesises the influence of a set of conditions related to the so-called 'knowledge transfer risk': constituent characteristics (i.e., the percentage of knowledge workers; the presence of time and spatial flexible work arrangements; and output management), cultural compatibility (flexible organisational culture), and management cognition (managers' perceived telework attributes relating to productivity; social cohesion; and work-life balance). Hypotheses are tested through a series of multivariate logistic regression analyses. Survey data were collected in 2003 among 407 firms. Our study shows that firms are more likely to integrate teleworking practices in their strategic HR management policies and introduce formal teleworking policies as a long-term investment in (highly-valued) personnel, when the knowledge transfer risk is lower and when they anticipate higher organisational commitment and productivity levels due to teleworking. These findings indicate direction for policy makers that aim to stimulate telework adoption and formalisation of fair telework policies.
\end{abstract}

Keywords: teleworking practices and policies; adoption and formalisation; knowledge transfer; socialisation; managerial attitudes; corporate culture.

Reference to this paper should be made as follows: Peters, P. and Batenburg, R. (2015) 'Telework adoption and formalisation in organisations from a knowlegde transfer perspective', Int. J. Work Innovation, Vol. 1, No. 3, pp.251-270.

Biographical notes: Pascale Peters holds a position as an Associate Professor at Radboud University Nijmegen (Institute for Management Research), the Netherlands. In 2000, she received her PhD at the Faculty of Social Science, Tilburg University, the Netherlands. As of December 2004, she has worked as Researcher and Lecturer at the Business School, Radboud University Nijmegen 
(Institute for Management Research), the Netherlands. Her main area of expertise relates to the flexible organisation of work, in particular, the adoption of home-based telework, New Ways to Work, and working carer support in organizations.

Ronald Batenburg obtained his Masters in Sociology at Utrecht University and his $\mathrm{PhD}$ in Social Sciences at Groningen University. He worked at the Social and Cultural Planning Office as Research Fellow, at Utrecht University as Post-Doc Researcher, at Tilburg University and Nijmegen University as Assistant Professor, as Associate Professor at Utrecht University and as Senior Research Consultant at Dialogic Innovation and Interaction. Since April 2009, he is Programme Coordinator Healthcare and Manpower Planning at NIVEL, the Netherlands Institute for Health Services Research. His research areas are labour market studies and transitions, as well as the socio-organisational aspects of ICT.

\section{Introduction}

Teleworking can be broadly defined as performing work activities that require the use of IT and that are performed remotely from the location where the results are delivered, either part-time or full-time [Taskin and Bridoux, (2010), p.2505]. Teleworking, or telecommuting, has attracted varying levels of interest since the 1970s (Bailey and Kurland, 2002). Despite that, the larger part of teleworking practices in organisations are marginal and not formalised (Van Klaveren et al., 2005), as they often result from ad hoc bottom-up initiatives (Peters et al., 2010). Current market and insitutional pressures, however, such as anticipated labour market shortages, technological developments, growing societal expectations regarding flexibility of work, and international and national telework regulations, are increasingly pressuring organisations to consider the adoption and implementation of formal teleworking in their strategic designs, as telework is widely believed to improve organisational effectiveness, efficiency and employee well-being on a long-term basis (cf. Peters, 2011; Shin et al., 1997). In fact, formalisation of substantial telehomeworking practices may be particularly important since potential telework advantages run parallel with severe disadvantages that call for regulation of the telework practice. One major disadvantage concerns "the potential harmful impact of telework on knowledge transfer in the organization" [Taskin and Bridoux, (2010), p.2504]. Therefore, more insight is needed into how conditions relating to this potential 'knowledge transfer risk' influence the adoption and formalisation of teleworking practices.

In light of the idea of isomorphism regarding the adoption of organisational policies and practices (Dimaggio and Powell, 1983), it is specifically interesting to focus on earlier telework adopting organisations. These early adopters can be assumed to have taken the potential 'knowledge transfer risk' into account in their telework decision-making. Moreover, particularly these organisations expected the numbers of teleworking practices in their firms to grow (Peters and Batenburg, 2004). Apparently, these organisations considered their organisational conditions to be more suitable for teleworking than others - but who are these organisations, and what were their considerations?

Telework research has often been critised for not being focused on theory-building, or on testing theory-driven hypotheses (Bailey and Kurland, 2002). The present study aims 
to contribute to the existing anthology of telework research literature by focusing on conditions that can be linked with Taskin and Bridioux' knowledge transfer theoretical perspective (2010), combined with insights from theories derived from the 'adoption literature' (cf. Cook, 2004), including the disruptiveness theory (Peters et al., 2010; Powell and Maniero, 1999), dependency theory (Klein et al., 2000), and managerial interpretation theory (Milliken et al., 1998). It uses data from a large scale survey held in 2003 amongst HR-managers and chief excutives in 407 large Dutch profit organisations to test hypotheses predicting differences in firms' adoption and formalisation of teleworking practices. As the home office can be viewed the most important alternative workplace (Gareis, 2002), the focus is on 'telehomeworking' practices and policies. Of course, telehomeworking may be combined with mobile work practices, such as working at clients' premisses, or with working at satellite offices or other flexible working places, such as provided by public transport, hotels, restaurants, et cetera. As the frequency of most substantial telehomeworking practices in the Netherlands does not exceed more than one or two days per week (Peters and Batenburg, 2004), the focus is on organisations' adoption of substantial telehomeworking practices, comprising one day or more per week on average.

\section{Theory and hypotheses}

\subsection{The knowledge transfer risk}

Knowlegde transfer allows knowlegde to be diffused across organisational members, and is, therefore, an important condition for collective knowledge creation underlying competitive advantage (Taskin and Bridoux, 2010). Knowledge tranfer is facilitated by organisational socialisation, "the process by which an individual learns the values, norms, and required behavioral patterns of a group" (p.2504). Two components can be distinguished: cognitive aspects of socialisation, including shared mental schemes, language and narratives, identification with organisational goals and values, and relational aspects of socialisation, such as close relationships. Moreover, a distinction can be made between "knowledge that is object of the transfer," so called "technical knowledge," and "knowledge that facilitates the transfer," so called "organizational social knowledge" (p.2504).

Based on Taksin and Bridoux' theoretical model, it can be assumed that a formal organisational telework policy may be developed to prevent teleworking from disrupting the intra-organisational work processes (cf. Powell and Maniero, 1999), particularly the organisational socialisation and knowledge transfer process (Taskin and Bridoux, 2010). When teleworking practices are formalised, teleworkers may need to sign a telework contract which more strickly regulates the telework practice via formal guidelines, for example, regarding: the physical location of the telework practice; the duration of the telework practice, such as the maximum number of teleworking days; the availability policy, including a minimum number of office days to garantuee face-to-face contact with peers, et cetera (Peters and Batenburg, 2004), to reduce the loss of knowledge transfer.

Moreover, formalisation of the telework practice might affect employees' and managers' perceptions of teleworking (cf. Taskin and Bridoux, 2010), as it legitmises the use of the teleworking practice. Hence, in addition to formal rules directly limiting 
disruptions of the knowlegde transfer process, the formalisation of teleworking may also indirectly restict disruptions, as formalisation might commit teleworkers to the organisation and stimulate them to reciprocate the benefits of teleworking by transfering their knowledge to other organisational members. Hence, telework adoption may not only depend on the disruptiveness of the teleworking practice, but also on dependency factors such as constituents' exchange relationship with the organisation and their relative power position (Klein et al., 2000; Peters et al., 2010).

\subsection{Hypotheses}

Based on the account given above, it can be assumed that organisations' telework decisions depend on their assessement of the 'knowledge transfer risk' associated with teleworking. Those organisations that expect knowledge transfer not to be disrupted too much are more likely to adopt and formalise teleworking practices. Also those searching to commit workers by allowing and legitimising teleworking may expect teleworkers to reciprocate by transferring knowledge and, therefore, may be more likely to adopt and formalise telework practices. Below, hypotheses, representing constituent factors, cultural factors, and management cognition factors, are developed, based on organisational conditions related to the organisational socialisation and knowledge transfer process as presented by Taskin and Bridoux (2010), affecting the adoption and formalisation of teleworking practices.

\section{Condition 1: the percentage of knowledge workers}

Professionals and other high-grade knowlegde workers may be regarded an important constituent group in organisations. As their work requires high levels of concentration and creativity, they may demand teleworking to escape from the hectic office. From a disruptiveness perspective, it can be argued that teleworking by professionals may bring about relatively little knowledge transfer costs as they have enjoyed a professional educational training program which has informed them about the cognitive components of the socialisation process, such as their job's technological aspects (cf. Taskin and Bridoux, 2010). In addition to professional socialisation, knowledge workers may read professional literature to update their task-related technical knowledge, expertise, skills and knowledge of customers (cf. Peters and Heusinkveld, 2010). From a dependency perspective, it can be argued that the adoption decision might be more favourable when workers contribute to the bottom line of the organisation (Klein et al., 2000). In fact, controling and monitoring their performances cannot be enforced by severe direct control and close supervision may even adversely affect professionals' creativity and productivity. Not responding to a professional's teleworking request may lead to a breach of the psychological contract, which may reduce commitment to the organisation in the short or longer run. In the same vein, allowing teleworking may increase the professional's commitment (Golden and Veiga, 2008), and hence may ensure professionals' commitment to knowledge transfer (Taskin and Bridoux, 2010). However, professional workers are also believed to generate new knowledge which needs to be transferred to the rest of the workers (Taskin and Bridoux, 2010). With an eye to the relational component of organisational socialisation, it can be expected that a formal telework policy may better garantuee that teleworking professionals transfer their knowledge to other organisational members. 
Based on the account given above, it can be expected that:

H1 Organisations employing a higher percentage of professional knowledge workers are more likely to have

a adopted

b formalised telework practices.

\section{Condition 2: the presence of time and place independent workers}

The presence of mobile workers and flexitime, the latter allowing employees to have more say regarding when to start and finish working, implies that some employees in the organisation are given higher degrees of time-spatial flexibility. These workers may also demand telehomeworking as it makes their time use more efficient. Both temporal and spatial flexibility may result in communication and management problems. However, in comparison with telehomeworkers, mobile workers have more opportunities to socialise at their clients' premises which may provide them sufficient knowledge to do their jobs remotely from the head office which reduces the knowledge tranfer risk. Yet, the presence of mobile and flexible workers indicates employees to work at a-typical physical and temporal locations, potentially reducing direct face-to-face contact with peers. Moreover, mobile workers are likely to work remotely more frequently than other teleworkers. In order to reduce the knowledge transfer risk, under the condition of mobile work and flexitime in organisations, regulation of the telework practice is more likely. Based on this, it was expeced that:

H2 Organisations employing flexible working times and mobile workers are more likely to have

a adopted

b formalised teleworking practices.

\section{Condition 3: output management}

Also the category of workers that are controlled and rewarded on the basis of their individual results, rather than on their actual 'face hours' at work, may be more likely to telework, as underperformance of these employees will be punished by rewarding them less, either directly by financial rewards, or indirectly by reduced career perspectives. Output management may avoid opportunistic behaviour and, therefore, reduces the need for close supervision (Illegems et al., 2001; Pérez Pérez et al., 2005). Also from a knowledge transfer perspective, setting targets and deadlines may reduce the need to share knowledge during the work process.

To further cover the knowledge transfer risk associated with output management, however, firms may want to invest in telework contracts, regulating communication, planning, and meeting formally or informally at work. In fact, output management can be easily incorporated in telework policies and may be part of a consistent HRM-bundle reducing the knowledge transfer risk. Based on the account above, the following hypothesis was formulated: 
H3 Organisations employing workers that are managed on the basis of output are more likely to have

a adopted

b formalised teleworking practices.

\section{Condition 4: teleworking culture}

Organisational socialisation is an important factor in knowledge transfer, but may be negatively affected by organisations' teleworking practices (Taskin and Bridoux, 2010). It is important for building the organisational culture, which guides feelings, thinking and acting of organisational members. Organisational culture can either be a stimulating or a restricting factor in organisations' telework decisions. Especially a corporate culture in which cognitive and relational components focus on direct control and face-to-face-contact can be considered a barrier with regard to the adoption of teleworking. The distinction between control, coordination, rules, formality, stability, and predictabilty, on the one hand, and flexibility, freedom, and dynamics, on the other, is the first dimension in the 'competing values framework' as distinguished by Robert Quinn (cf. Cameron and Quinn, 1999). The second dimension of this framework consists of the distinction between internal orientation, integration and uniformity, on the one hand, and external orientation, differentiaton and competiveness, on the other. Based on these two dimensions, four ideal-typical organisational cultures can be distinguished, which can be related to organisations' telework decision-making (Standen, 2000). Within a so-called 'family'-culture, teleworking can be viewed as a flexible work mode allowing for a humane work environment, higher commitment and, ultimately, higher productivity levels. Within an 'adhocracy'-culture, teleworking may be viewed as a means for giving employees more freedom to be creative and to concentrate. However, also within a 'market'-culture, teleworking may be employed, although temporarily, in order to replace staff personnel, to reduce overhead costs, or to increase the firm's flexibility. Also within a 'hierarchy' culture, teleworking might be allowed, yet only occasionally and marginally. Given their emphasis on control, Standen (2000) considered the market and the hierarchy culture to be less suitable for teleworking than the family and adhocracy-culture. In line with this, his empirical research showed that organisations characterised by cultural values that do not emphasise control were more likely to adopt teleworking practices. In such cultures, traditional management ideas advocating bureaucratic and Tayloristic management principles have been replaced by mental schemes and discourses allowing more employee flexibility and autonomy. Exactly these factors may foster incentives to increase teleworkers' commitment to the organisation and stimulate to put more effort in their jobs, which may positively affect knowledge transfer.

In order to further back up 'trust' in teleworkers, the knowledge transfer risk can be reduced and commitment increased by developing a formal telework policy. As organisations are more likely to adopt an HRM practice when it fits with the internal organisational characteristics, organisational culture can be expected to stimulate organisations to formalise its teleworking practices.

On the basis of the account given above, it can be hypothesised that: 
H4 Firms that are characterised by a flexible organisational culture (i.e., a family or adhocracy culture) are more likely to

a adopt

b formalise teleworking practices.

\section{Condition 5: management perception of teleworking}

Telework literature (Taskin and Bridoux, 2010; Taskin and Edwards, 2007) suggests managers' perceptions of teleworking to be an important bottleneck or driver with respect to the introduction and uptake of teleworking practices (cf. Milliken et al., 1998). Managers, viewed as intentional and pro-active agents, may subjectively assess the consequences of teleworking for the organisational socialisation process, and may have various interpretations of the associated knowledge transfer risk, possibly depending on their own backgrounds and objectives. Particularly managers who are in a position to introduce teleworking, like CEOs, or to judge teleworking requests, like HR-managers or line managers, can influence organisations' informal and formal practices regarding teleworking. Managers who are well-disposed towards teleworking could even function as champions of teleworking (Ruppel and Howard, 1998).

Besides fearing a loss of control when employees work at home, managers may also worry about workers becoming professionally and socially isolated (Cooper and Kurland, 2002). Managers who do not anticipate teleworkers to become socially isolated, however, might also expect intra-organisational knowledge transfer not to be affected (cf. Taskin and Bridoux, 2010), which likely affects the adoption of teleworking practices in the organisation. This might also be signaled in managers' expectations that productivity can gain from teleworking due to better work concentration. Also the fact that managers expect teleworking to improve employees' work-life balance might imply that they expect teleworkers to reciprocate these employee benefits by transfering their knowledge to other organisational members (cf. Taskin and Bridoux, 2010). Commitment and reciprocity may be further stimulated by implementing a formal telework policy.

Based on the reasoning above, the following fifth and final hypothesis is formulated as:

H5 Firms in which managers are well-disposed towards the social consequences of teleworking, the productivity gains associated with teleworking, and towards the consequences for employees' work-life balance, are more likely to

a adopt

b formalise teleworking practices.

\section{Methodology}

\subsection{Data and method}

This study uses data collected through a written organisation questionnaire, entitled 'Choices regarding time and place: modern working conditions in Dutch organisations', conducted in 2003 (cf. Hillebrink et al., 2008). Precisely 3,000 addresses were randomly selected from an address file from the Dutch Chamber of Commerce. The address file 
contained a list of private organisations employing at least 100 workers. The questionnaires were sent to the Personnel Departments of the 3,000 organisations. After three weeks, a reminder was sent. All together, 604 questionnaires were returned. In most cases, the questionnaires were filled out by (senior) HR-managers. About $20 \%$ of the respondents were chief executives $(20.1 \%)$. About $86 \%$ of the respondents were highly educated (high vocational education or academic education) and $40 \%$ was female. The response rate was $20.1 \%$.

The initial dataset comprised a total of 517 cases. In order to judge whether this dataset represents our research population, the response was compared with the distribution across industry categories and organisational size categories as presented by the Dutch Statistics Bureau. For the scope of our research, the agricultural and hospitality industry were not analysed. The industrial companies appeared to be particularly overrepresented (38\% versus 9\% according to the Dutch Central Bureau of Statistics). Moreover, the larger organisations were overrepresented. To correct for differences between response and population figures, weight factors were calculated, taking into account the actual distribution of organisations across sector and size, enabling us to calculate telework adoption and formalisation. However, for the desriptives of the variables in our dataset, the correlation analyses and the logistic regression analyses, the unweighted data were used, as we were primarily interested in testing hypotheses regarding the relationships between variables. Since our hypotheses are directed, these were tested one-tailed.

\subsection{Adoption and formalisation of teleworking practices}

In the questionnaire, teleworking was defined as "the situation in which an employee works at home during contractual working hours for at least one day per week." Two dichotomous variables were constructed indicating the adoption of teleworking practices and policies in the organisation: teleworking is allowed (at least for part of the personnel) $(1=$ yes $)$ and the firm's teleworking policy is formalised $(1=$ yes $)$. Weighted (descriptive) analysis showed that $8.3 \%$ companies out of the total sample had a formal policy, and $5.7 \%$ out of the total sample were preparing or doing a telework pilot. More than half of the organisations (58\%) did not have a formal teleworking policy, but allowed teleworking informally. For the larger part, only selections of their personnel (about $10 \%$ on average) were given access to teleworking, mostly one teleworking day per week. In $28 \%$ of the organisations, teleworking was not adopted at all. Note, however, that the public sector, the agricultural sector and the hospitality industry were not taken into account. Moreover, the study only related to larger organisations (100 employees or more). In addition, the use of IT was not mentioned in our definition. Of course, it should be realised that IT is an important enabler of distance working and, therefore, it is often used in the definition of teleworking. However, since the main focus in this study is on management aspects affecting distance working, the percentage of employees in the organisation working with a computer was included as a control variable (see below). Importantly, when aksing about the organisations' teleworking practices, no restrictions were mentioned with respect to the minimal number of actual teleworkers in the firm.

In conclusion, to be better able to explain whether organisations allow teleworking practices in their organisation, and, if so, whether these practices are accompanied by a formal teleworking policy, organisations preparing, or doing a telework pilot were 
excluded from the analyses. This allowed us to distinguish between two more or less homogeneous groups of organisations: on the one hand, organisations that had implemented formal teleworking policies; on the other hand, organisations that were not (yet) planning to introduce a formal teleworking policy, leaving a total of 490 cases for further analyses.

\subsection{The five conditions}

- Condition 1: the percentage of knowledge workers was measured by regarding the ' $\%$ highly educated workers' as an indicator for high-grade professional workers with a high level of job autonomy. In the descriptive and multivariate analyses, the logarithm of this variable was used.

- Condition 2: the presence of time and place independent workers was measured by two variables: the dichotomous variables 'mobile workers in the organisation' (1 = yes); and 'flexible working hours' $(1=$ yes $)$.

- Condition 3: output management was measured through the dichotomous variable 'individual bonus/output related rewards' $(1=$ yes $)$.

- Condition 4: teleworking culture was assessed with Quinn's (shortened) instrument on organisational culture, asking respondents to respond to three different issues (leadership, management style and cohesion) and to distribute 100 points to propositions/answering categories (A, B, C, D). Proposition A corresponded with a family culture, $\mathrm{B}$ with adhocracy, $\mathrm{C}$ with a hierarchy culture, and $\mathrm{D}$ with a market culture. Based on the scores obtained from the propositions, it was determined what type of culture pictured the organisational culture best. Since the two teleworkingculture-hypotheses focused on the dimension 'flexibility versus control,' the scores on the A-items (family culture) and the B-items (adhocracy-culture) were added up. A higher score on the new, continuous variable 'teleworking culture' was taken to reflect a more flexible (and hence, a more teleworkable) organisation culture.

- Condition 5: management perception of teleworking was assessed by the following eight items (Likert scales):

1 teleworking decreases mutual learning among employees

2 teleworking decreases cooperation amongst employees

3 teleworking leads to isolation of employees

4 teleworking decreases employees' organisational commitment

5 teleworking increases productivity

6 teleworking improves employees' concentration

7 teleworking increases employees' motivation

8 teleworking is a proper solution for supporting employees with respect to the combination of work and family life.

Factor analysis (PAF, Oblimin) showed items (1) to (7) to represent two factors. The items (1) (learning), (2) (cooperation), (3) (isolation) and (4) (commitment) were found to load on a factor representing the respondent's view on the 'social consequences of teleworking' (Cronbach's alpha $=0.78)$. The items (5) (productivity), (6) (concentration) 
and (7) (motivation) comprised one factor indicating the respondent's view on the assumed 'productivity gains' of teleworking (Cronbach's alpha $=0.68)$. Note that all items were (re)coded so that a higher score represents a more positive disposition towards teleworking. The item on 'work-family combination' was used as a single indicator of the organisation's perceived importance of teleworking for employees' work-life balance. Note that this item was responded to most favourably ( $66 \%$ of the managers agreed to this proposition). Although the 'social consequences' and 'productivity' scales correlated relatively highly $(0.48)$, the two subscales were used separately since they emphasise different aspects of managers' telework attitudes. In the multivariate analyses, the centred scores were used.

\subsection{Control variables}

In order to check whether other factors might affect the adoption and formalisation of teleworking practices, we introduced several control variables.

First, the analyses were controlled for the so-called 'technical readiness for telework' of the work activities performed by the workforce as an indicator for the possibility of IT-mediated knowlegde transfer in case teleworking practices were adopted. Moreover, although IT-interactions with coworkers may be less direct, it may also allow more formalised communications (Taskin and Edwards, 2007), which supports the formalisation of telework practices. Therefore, the continuous variable '\% PC-use within the organisation' was used $(\min =0 ; \max =100 ;$ mean $=57.54 ; S D=31.36)$, as we expected teleworking to be more likely when a higher percentage of the employees in the organisation worked with a personal computer (PC). Correlation analysis showed the correlation between the rate of highly educated workers and the rate of computer use to be high, but not too high (Pearson correlation= 0.66). Moreover, deleting the variable from the analyses did not affect the results.

Second, the analyses were controlled for organisational size. Therefore, the logarithm of the variable 'organisational size' was used $(\min =4.61$; $\max =9.68$; mean $=5.72$; $S D=0.90$ ). After all, larger organisations may have more potential teleworkers, and, consequently, face economies of scale when adopting and formalising teleworking practices. Moreover, they may have larger financial budgets for introducing formal teleworking policies. Also, larger firms are more visible and, therefore, receive more external pressure to adopt innovative work modes (Cook, 2004).

Third, the analyses were checked for the sector the organisation can be related to. Therefore, a dummy variable 'sector' was calculated. In some sectors, especially in service and consultancy, teleworking is known to be much more common than in other sectors (Van Klaveren et al., 2005). In the analyses, the service sector $(22.9 \%$ in our study) was used as the reference category to the other sectors, i.e.: 'industry' $(37.6 \%)$; 'building' (12.2\%); 'trade' (9.2\%); 'transport, logistics and communication' (7.5\%); 'financial sector' (6.5\%); and 'health and well-being' (4.1\%).

\subsection{Multicollinearity}

In order to analyse the potential problem of multicollinearity, the sizes of the variance inflation factors (VIF) were considered. The VIF-factors ranged from 1.065 (telework culture) to 2.412 (percentage of employees using a computer during work). As a rule of thumb, multicollinearity is high when the VIF factor exceeds 5. In our data, the 
VIF-factors were no higher than 2.412, indicating that multicollinearity was not too high. Also the bivariate correlations (see Table 1) showed no multicollinearity. Besides bivariate correlations, Table 1 shows the minimum and maximum scores and the mean scores of the dependent and independent variables used in the study.

\subsection{Common method variance}

To control for the potential effects of common method variance (Podsakoff et al., 2003) in the questionnaire, we applied different response formats for the measurements of the variables in our models. With regard to the attitude variables, for example, we used Likert-scales for a set of single items, whereas the culture-variable was measured through a variable measuring the extent to which the culture in the organisation can be characterised as flexible. Other variables were measured through a numerical entry (e.g., the percentage of higher educated employees in the firm, and computer use in the firm), or single choice questions (e.g., the presence of an individual bonus system, mobile workers, and flexitime).

In addition, we employed the statistical program AMOS to control for the effects of an unmeasured latent methods factor (common method variance-factor) on the interval and ratio scaled variables that we presented above. We estimated a model including the latent CMV-factor as suggested by Podsakoff et al. (2003). This model, we compared with a nested model excluding the latent CMV-factor. Both models fitted the data well. The model without the CMV-factor showed the following results: chi-square $=49.077$; $f=38$; probability level $=0.108$. The model including the CMV-factor showed a chi-square of $39.092(d f=29$; probability level $=0.100)$. The analyses showed the CMV-factor not to affect the scores on the variables in our model significantly, which implies that our findings were not much affected by the problem of common method variance. Moreover, the standardised regression estimates showed the CMV-factor only to contribute to a small proportion of the variance of the manifest variables, the lowest proportion being $0.0841 \%$, the highest proportion being $20.6 \%$. Finally, the information criteria of the default models showed that the model without the CMV-factor fit the data better than the model including the CMV-factor, which was shown by the lower scores on the Information Criteria of the model without the CMV-factor.

\section{Results}

\subsection{Descriptive analyses}

In Table 1, the descriptives and bivariate correlations of the dependent and independent variables are presented. Bivariate correlations showed that the organisation's decision to adopt (informal and/or formal) teleworking practices was positively correlated with the proportion of highly educated employees in the workforce; the presence of mobile workers; flexible working hours; and output-related rewards. Whereas culture did not significantly correlate with the adoption of teleworking practices, managers' attitudes towards the consequences of teleworking for social aspects and productivity did. Strikingly, the belief that teleworking helps employees to balance work and family did not correlate significantly with the adoption of teleworking. 
Table 1 Minimum score ( $\min$ ), maximum score (max), mean score (mean), standard deviation $(\mathrm{SD})$ and bivariate correlations between variables $(\mathrm{N}=490)$

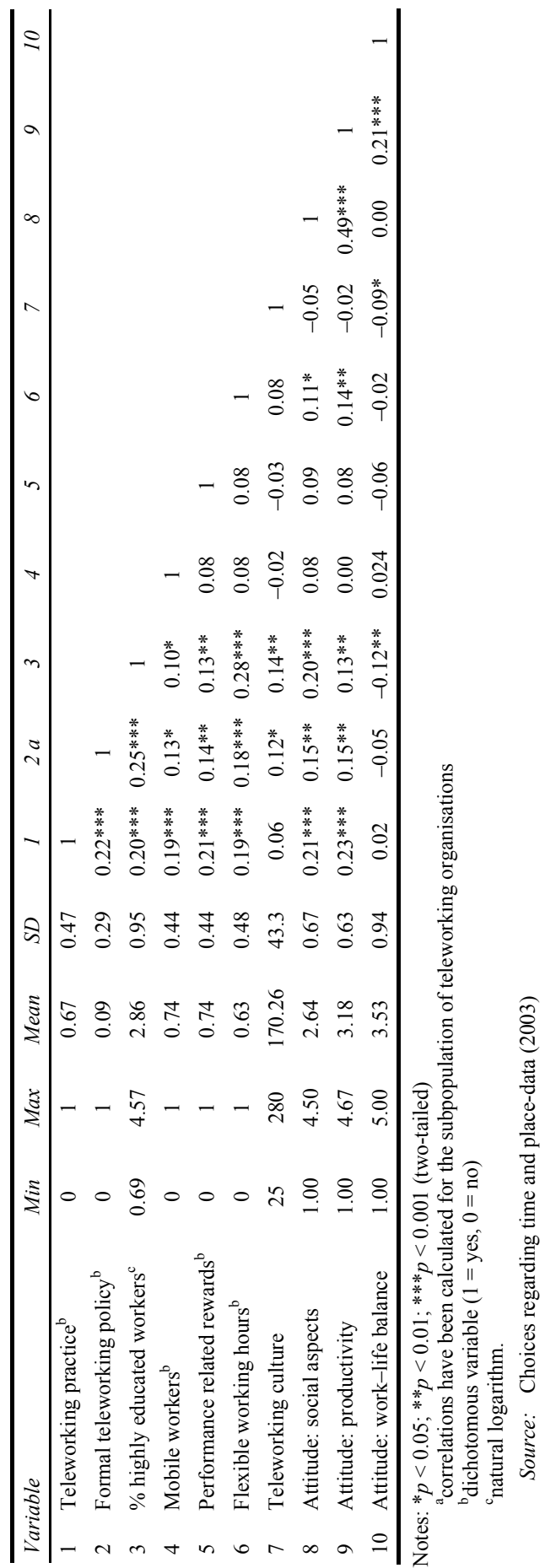




\subsection{Explanatory analyses}

The results of the multivariate analysis explaining the adoption of (formal and/or informal) teleworking practices are presented in Table 2. It shows that teleworking adoption was more likely to occur when:

1 employees are rewarded on the basis of their individual output

2 organisations employ mobile workers

3 employees' working hours are more flexible

4 managers hold more positive expectations of teleworking with respect to employees' productivity and social consequences.

Table 2 Logistic regression coefficients ${ }^{\mathrm{a}}$ explaining the adoption of teleworking practices $(\mathrm{N}=487)$

\begin{tabular}{|c|c|c|}
\hline & $B$ & $S E(B)$ \\
\hline \multicolumn{3}{|l|}{ Constituent factors } \\
\hline$\%$ highly educated workers in the organisation ${ }^{c}$ & 0.030 & 0.182 \\
\hline Mobile workers in the organisation ${ }^{\mathrm{b}}$ & $0.686^{* *}$ & 0.278 \\
\hline Individual bonus/performance related rewards ${ }^{\mathrm{b}}$ & $1.199 * * *$ & 0.281 \\
\hline Flexible working hours ${ }^{\mathrm{b}}$ & $0.511^{*}$ & 0.263 \\
\hline \multicolumn{3}{|l|}{ Teleworking culture variable } \\
\hline Teleworking culture & 0.001 & 0.003 \\
\hline \multicolumn{3}{|l|}{ Management cognition variables } \\
\hline Teleworking attitude (social work aspects) & $0.484 *$ & 0.227 \\
\hline Teleworking attitude (productivity) & $0.516^{*}$ & 0.223 \\
\hline Teleworking attitude (work-life balance) & -0.155 & 0.142 \\
\hline \multicolumn{3}{|l|}{ Control variables } \\
\hline \multicolumn{3}{|l|}{ Industry (reference group $=$ services) } \\
\hline Manufacturing & $-0.673^{*}$ & 0.374 \\
\hline Construction & -0.581 & 0.479 \\
\hline Retail & $-1.219^{* *}$ & 0.466 \\
\hline Transport & $-0.954^{*}$ & 0.515 \\
\hline Financial services & -0.072 & 0.626 \\
\hline Healthcare & 0.494 & 0.908 \\
\hline Number of employees in organisation ${ }^{\mathrm{c}}$ & -0.237 & 0.148 \\
\hline$\%$ employees working with computer & -0.004 & 0.006 \\
\hline Constant & 1.090 & 1.123 \\
\hline Model fit & Chi-square $=74.426^{* * *}$ & $D f=16$ \\
\hline
\end{tabular}

Notes: ${ }^{*} p<0.05 ; * * p<0.01 ; * * * p<0.001$ (hypotheses tested one-tailed)

aunstandardised regression coefficients $(B)$ and standard errors $[S E(B)]$

${ }^{\mathrm{b}}$ dichotomous variable $(1=$ yes, $0=$ no $)$

'natural logarithm Nagelkerke $R$-square: $23.8 \%$.

Source: Choices regarding time and place-data (2003) 
Contrary to what was expected, the variables representing the manager's perception of teleworking providing employees a better combination of work and private life, organisational culture, and the percentage of higher educated workers in the firm, did not play a significant role.

The results of the logistic regression analysis explaining the adoption of a formal teleworking policy are presented in Table 3. In line with our expectations, all conditions hypothesised were statistically significant and positively related with the likelihood of a formal teleworking policy. Yet, with respect to management cognition, only managers' beliefs regarding productivity appeared to play a significant and positive role: organisations anticipating productivity gains were more likely to have adopted a formal teleworking policy.

Table 3 Logistic regression coefficients ${ }^{\mathrm{a}}$ explaining the adoption of a formal teleworking policy $(\mathrm{N}=328)$

\begin{tabular}{|c|c|c|}
\hline & $B$ & $S E(B)$ \\
\hline \multicolumn{3}{|l|}{ Constituent factors } \\
\hline$\%$ highly educated workers in the organisation ${ }^{c}$ & $0.718^{*}$ & 0.385 \\
\hline Mobile workers in the organisation ${ }^{\mathrm{b}}$ & $1.221 *$ & 0.732 \\
\hline Individual bonus/performance related rewards ${ }^{\mathrm{b}}$ & $1.412 *$ & 0.821 \\
\hline Flexible working hours ${ }^{\mathrm{b}}$ & $1.235^{*}$ & 0.623 \\
\hline \multicolumn{3}{|l|}{ Teleworking culture variable } \\
\hline Teleworking culture & $0.011^{*}$ & 0.005 \\
\hline \multicolumn{3}{|l|}{ Management cognition variables } \\
\hline Teleworking attitude (social work aspects) & 0.185 & 0.332 \\
\hline Teleworking attitude (productivity) & $0.995^{* *}$ & 0.419 \\
\hline Teleworking attitude (work-life balance) & -0.118 & 0.184 \\
\hline \multicolumn{3}{|l|}{ Control variables } \\
\hline \multicolumn{3}{|l|}{ Industry (reference group $=$ services) } \\
\hline Manufacturing & -0.678 & 0.570 \\
\hline Construction & -0.798 & 0.929 \\
\hline Retail & 0.664 & 0.716 \\
\hline Transport & 0.862 & 0.888 \\
\hline Financial services & -0.337 & 0.707 \\
\hline Healthcare & -20.043 & $10,850.226$ \\
\hline Number of employees in organisation ${ }^{c}$ & -0.038 & 0.228 \\
\hline$\%$ employees working with computer & -0.005 & 0.011 \\
\hline Constant & $-8.888^{* * *}$ & 1.935 \\
\hline Model fit & Chi-square $=56.384 * * *$ & $D f=16$ \\
\hline
\end{tabular}

Notes: ${ }^{*} p<0.05 ; * * p<0.01 ; * * * p<0.001$ (hypotheses tested one-tailed)

anstandardised regression coefficients $(B)$ and standard errors $[S E(B)]$

${ }^{\mathrm{b}}$ dichotomous variable $(1=$ yes, $0=$ no $)$

c natural logarithm Nagelkerke $R$-square: $32.4 \%$.

Source: Choices regarding time and place-data (2003) 


\section{Discussion and conclusions}

Triggered by the notion that teleworking in organisations appears to remain an eternal promise, this study has deepened a set of conditions associated with the 'knowledge transfer risk' that may influence a firms' adoption and formalisation of teleworking practices. In this final section, we will summarise and discuss our findings and elaborate on these.

\subsection{Adoption and formalisation of teleworking practices}

Although the higher percentage of highly educated (professional knowledge) workers was not shown to be a factor in the adoption of (formal or informal) teleworking practices, it was a significant condition regarding the formalisation of teleworking practices in organisations having adopted teleworking practices. Hence, lower percentages of highly educated (professional knowledge) workers appeared to suffice to exert internal pressures on organisations to adopt teleworking practices. From a knowledge transfer perspective, telehomeworking for these workers might not severely mitigate the knowledge transfer process as it comes to technical knowledge and may even foster these workers' commitment to the organisation, and hence, knowledge transfer. The latter finding, however, indicates that the percentage of highly educated (professional knowlegde) workers in the organisations does play a role in organisations' telework formalisation decisions. Possibly, as more workers in the organisation can be expected to be able to and to request remote work, the organisation is more likely to regulate the telehomework practice. From a knowledge sharing perspective, this may be taken to mean that the formalisation of the telework practices in organisations employing a higher percentage of highly educated (professional knowledge) workers may reduce the knowledge transfer risk. From a dependency perspective, it can be argued that due to the formalisation of telehomeworking practices, knowledge workers might perceive organisational support for telehomeworking and, reciprocate by being more commited to the organisation, safeguarding organisational knowledge transfer. In other words, investing in a formal teleworking policy can be viewed an investment in the firm's human capital, not only to control the knowlegde transfer process across workers, but, in line with the institutional and resource dependence theory (Dimaggio and Powell, 1983; Klein et al., 2000), also to commit them to this process. Also, investing in telework technology, which might be part of the formalisation of teleworking practices, would better garantuee that ability of employees to socialise and adequately share knowledge. Furthermore, the formalisation of the telework practice may stimulate managers' and employees' social justice perceptions, as it provides both parties with guidelines to manage the telework relationship.

The presence of time and place independent workers in the organisation was possitively related to the odds of having adopted and formalised teleworking practices. This supports our expectations that the presence of mobile workers would imply that they may be potential telehomeworkers. Adopting telework practices in that case could be taken to mean that this type of workers are expected to be partly socialised at their principals' premises, which reduces the knowledge transfer risk. Moreover, it can be argued that mobile workers are expected to work remotely more frequently than other 
telehomeworkers, which might have called for a formalisation of the telework practice to reduce the knowledge transfer risk.

Also the presence of output management was shown to affect the adoption and formalisation of telework practices. On the one hand, output management can be considered to reduce the knowledge sharing risk, as under this condition, employees have knowledge about what is expected from them. The higher odds of formalisation of telework practices may be explained by the fact that output management can be easily aligned with the adoption of a formal telework policy. Of course, output management may also have resulted from actions undertaken by the organisation to mitigate the negative consequences of teleworking. (cf. Taskin and Bridoux, 2010).

No support was found for the influence of a flexible organisational (telework) culture on organisations' adoption of teleworking practices as such. This finding is not in line with our expectation that a flexible culture would be an important condition to mitigate the potential knowledge transfer risk of telehomeworking. It should be remembered, however, that our analysis was targeted at analysing the presence of telehomeworking practices in firms, regardless of the number of employees taking advantage of this practice. Obviously, a flexible culture may not be a necessary condition for giving access to telework to a part of the organisation's workforce. As Standen (2000) already pointed out, teleworking can be expected to be most compatible with a flexible culture, but also within other organisational cultures it may be adopted, be it probably for other reasons, durations, and in different numbers (ibid.). However, our analyses demonstrated that organisations characterised by a more flexible organisational culture were indeed more likely to have introduced formal teleworking policies. Although it was not clear from our analyses whether this flexible culture was in place before the formalisation of teleworking practices, or whether it has resulted from a deliberate organisational change program, this finding can be explained from the dependency perspective, stressing the growing importance of employee commitment and individuality also fitting the teleworking practice. Moreover, the offering of a formal teleworking policy can be regarded a signal to (highly valued) employees that the organisation trusts its employees and acknowledges their growing demand for job autonomy and time-spatial flexibility (cf. Yap and Tng, 1990). The introduction of a formal teleworking policy can also be viewed an expression of organisational concern for workers, since it prevents workers from the unintended side effects of informal teleworking practices. As stressed in the European Telework Agreement, a formal telework policy, for example, may give teleworkers financial compensation for IT-equipment or tax reductions and the same rights as non-teleworkers (cf. Peters, 2011).

Managers' perceptions of the telework arrangement regarding productivity and social cohesion were found to provide an additional explanation for the adoption and formalisation of teleworking practices in organisations. This is in line with other research that stressed the importance of management support (Illegems and Verbeke, 2004; Taskin and Edwards, 2007). Especially organisations in which the managers (in our study CEO's or HRM managers) expected higher productivity resulting from teleworking were more likely to have invested in formal telework policies, possibly either to reduce disruptiveness of knowledge transfer by means of regulations, or to improve knowledge transfer by commiting employees by giving formal telework access and official managerial support to teleworkers.

Managers' perceptions of the knowlegde sharing risk was also taken to be signalled by their expectations of social costs associated with teleworking, including consequences 
concerning commitment, workers' isolation, cooperation and learning-on-the-job (Marshall et al., 2007), as a loss of social cohesion might affect both the cognitive and relational components of organisational socialisation, and hence, knowledge transfer. Strikingly, however, perceived social costs were a factor in organisations' decisions to allow teleworking, but it did not significantly affect its formalisation. This is striking, since, with an eye to knowledge transfer, we expected a formal telework policy to be implemented to (further) safeguard or to strengthen the social cohesion at work.

Although a relatively high percentage of the managers in our study $(66 \%)$ considered teleworking to contribute to employees' work-life balance, this perception was not a factor in organisations' adoption and formalisation of teleworking practices. May be, most managers do not view the achievement of a better work-life balance as a decisive telework attribute that directly adds to the goal of the organisation (Powell and Maniero, 1999). This is in line with the telework literature stating that managers perceive telework to have more advantages for employees than for the organisation (Pérez Pérez et al., 2002).

\subsection{Limitations and research implications}

Although we believe that our analyses are solid and robust in their outcomes, there are some points for further consideration.

First, our study relied on Dutch organisational data of large, private companies. Consequently, our hypotheses and results related to organisational characteristics rather than characteristics of individual employment relationships. Our design and operationalisations can, therefore, explain some of the unexpected outcomes of the study, for instance those with regard to educational level and organisational culture as discussed above. Future research might examine whether the knowledge transfer risk is also perceived by employees, for example through network analysis focusing on knowledge transfer between teleworking and non-teleworking team members, and how this affects their telework adoption. Moreover, a (longitudinal) multi-level design would allow to link organisational, manager, team and employee level variables to the decision making process regarding teleworking issues, such as earlier suggested in the theoretical article by Peters and Den Dulk (2003) and already empirically illustrated by Peters et al. (2010) with regard to managerial decision making regarding granting employees' telework requests. Future research could use a multi-level design to analyse organisations' telework adoption and formalisation decisions across national contexts, possibly taking into account constituent factors of the national work force, national cultural factors, organisational characteristics, such as traditional and innovative management control practices (e.g., selection, training, output management, organisational culture and practices), et cetera.

Second, we used a cross-sectional and quantitative design and, based on data collected in 2003, testing whether constituent factors, organisational culture, and management cognition were associated with existing teleworking practices and policies. At that time, some firms had started as the front runners in telework adoption, while other firms were probably set to learn from the early adopters' risks and experiences. It would be interesting to find out whether the conditions affecting the knowledge transfer risk, and hence telework adoption and formalisation, have changed over time, as the telework field is moving fastly and market and institutional pressures, including mimetic pressures, 
are severe (cf. Peters, 2011). Of course, also to specifically disentangle cause and effect in our hypotheses, a longitudinal or panel design is required. Moreover, to further analyse the knowledge transfer risk affecting organisations' adoption and formalisation of teleworking practices, qualitative case studies may be needed to study the interplay between these factors in the telework decision-making process. This might plea for both quantitive and qualitative studies of teleworking organisations over time, to investigate whether our results hold when the dynamics of decision making and organisational change with respect to teleworking practices and policies are analysed. Moreover, a qualitative study may also allow to focus more on the exact content of the implemented telework policy, which was not taken into account in the present study.

Third, and finally, in view of the knowledge sharing risk associated with teleworking, multiple interventions from the organisation may be required. Both objective firm characteristics (constituent factors and organisational culture) and subjective factors (i.e., management cognition) were shown to play a role in teleworking adoption. These findings may indicate directions for intervention studies in collaboration with policy makers that aim to stimulate telework adoption and formalisation of telework policies in organisations. Generally, the odds of formal teleworking being offered are higher when the company employs a higher percentage of knowledge workers. However, output management and creating a flexible and supportive culture may also be employed to reduce the knowledge transfer risk associated with teleworking of other consituent groups (e.g., lower educated workers) that are not the usual suspects of teleworking, also within the public sector characterised by more bureaucracy (cf. Taskin and Edwards, 2007). Based on the insights from this study, conditions may be created that open up telework possibilities for other groups, which might also increase perceptions of justice and fairness regarding teleworking policies within and across organisations and sectors. Also managerial perception may be a point of departure for policy makers who are willing to stimulate the adoption and formalisation of teleworking. Emphasising the benefits of teleworking may be a good strategy to convince key actors, like CEOs who might for example be more vulnerable to productivity arguments (Peters and Heusinkveld, 2010), to stimulate the adoption process. In order to further study these issues, internal stakeholders' perceptions of informal and formal telework arrangements could be studied, developing a combined theoretical perspective, for example including justice and fairness arguments, and how these interact with multiple actors' dependency, disruptiveness, and institutional pressure arguments for or against the adoption, formalisation, and a particular content of teleworking practices in the organisation.

\section{References}

Bailey, D.E. and Kurland, N.B. (2002) 'A review of telework research; findings, new directions, and lessons for the study of modern work', Journal of Organizational Behavior, Vol. 23, No. 4, pp.383-400.

Cameron, K.S. and Quinn, R.E. (1999) Diagnosing and Changing Organizational Culture, Addison-Wesley, Reading, MA.

Cook, A. (2004) 'Corporate decision-making process: how organizations decide to adopt work/life initiatives' [online] http://wfnetwork.bc.edu/encyclopedia_entry.php?id=225andarea=All.

Cooper, C.D. and Kurland, N.B. (2002) 'Telecommuting, professional isolation, and employee development in public and private organizations', Journal of Organizational Behavior, Vol. 23, No. 4, pp.511-532. 
DiMaggio, P. and Powell, W. (1983) 'The iron cage revisited: Institutional isomorphism and collective rationality in organizational fields', American Sociological Review, Vol. 48, No. 2, pp.147-160.

Gareis, K. (2002) 'The intensity of telework in 2002 in the EU, Switzerland and the US', Presentation held at the New Work 2002 - Annual International Telework Forum Congress in Badajoz, Spain, 3-5 September [online] http:www.empirica.com/publikationen/2002_en.htm.

Golden, T.D. and Veiga, J.F. (2008) 'The impact of superior-subordinate relationships on the commitment, job satisfaction, and performance of virtual workers', Leadership Quarterly, Vol. 19, No. 1, pp.77-88.

Hillebrink, C., Schippers, J., Van Doorne-Huiskes, A. and Peters, P. (2008) 'Offering choice in benefits: a new Dutch HRM arrangements', International Journal of Manpower, No. 1, pp.304-322.

Illegems, V. and Verbeke, A. (2004) 'Telework: what does it mean for management?', Long Range Planning, Vol. 37, No. 4, pp.319-34.

Illegems, V., Verbeke, A. and Segers, R. (2001) 'The organizational context of teleworking implementation', Technological Forecastign and Social Change, Vol. 68, No. 3, pp.275-291.

Klein, K.J., Berman, L.M. and Dickson, M.W. (2000) 'May I work part-time? An exploration of predicted employer responses to employee request for part-time work', Journal of Vocational Behavior, Vol. 57, No. 1, pp.85-101.

Marshall, G.W., Michaels, C.E. and Mulki, J.P. (2007) 'Workplace isolation: exploring the construct and its measurement', Psychology and Marketing, Vol. 24, No. 3, pp.195-224.

Milliken, F.J., Martins, L.L. and Morgan, H. (1998) 'Explaining organizational responsiveness to work-family issues: the role of human resource executives as issue interpreters', Academy of Management Journal, Vol. 41, No. 5, pp.580-592.

Pérez Pérez, M., Marínez Sánchez, A.M. and De Luis Carnicer, M.P. (2002) 'Benefits and barriers of telework: Perception differences of human resource managers according to company's operations strategy', Technovation, Vol. 22, No. 12, pp.775-83.

Pérez Pérez, M., Marínez Sánchez, A.M., De Luis Carnicer, M.P. and Vela Jiménez, M.J. (2005) 'The difference of firm resources and the adoption of teleworking', Technovation, Vol. 25, No. 12 , pp.1476-483.

Peters, P, Den Dulk, L. and De Ruijter, J. (2010) 'May I work from home? Views of the employment relationship reflected in line managers' telework attitudes in six financial-sector organizations', Equality, Diversity and Inclusion: An International Journal, Vol. 29, No. 5, pp.517-531.

Peters, P. (2011) 'Flexible working time arrangements: exchange of good practice', Discussion Paper, the Netherlands [online] http://ec.europa.eu/justice/gender-equality/tools/goodpractices/index_en.htm.

Peters, P. and Batenburg, R. (2004) 'Dilemma's in het thuiswerkbeleid van Nederlandse bedrijven: Nieuwe punten voor de HRM-agenda', Tijdschrift voor HRM, Vol. 3, No. 3, pp.25-48.

Peters, P. and Den Dulk, L. (2003) 'Cross cultural differences in managers' support for home-based telework. A theoretical elaboration', International Journal of Cross Cultural Management, Vol. 3, No. 3, pp.329-346.

Peters, P. and Heusinkveld, S. (2010) 'Institutional explanations for managers' attitudes towards telehomeworking', Human Relations, Vol. 63, No. 1, pp.1-29.

Podsakoff, P.M., MacKenzie, S.B., Lee, J.Y. and Podsakoff, N.P. (2003) 'Common method biases in behavioral research: a critical review of the literature and recommended remedies', Journal of Applied Psychology, Vol. 88, No. 5, pp.879-903.

Powell, G.N. and Maniero, L.A. (1999) 'Managerial decision making regarding alternative work arrangements', Journal of Occupational and Organisational Psychology, Vol. 72, No. 1, pp.41-56. 
Ruppel, C.P. and Howard, G.S. (1998) 'Facilitating innovation adoption and diffusion: the case of telework', Information Resources Management Journal, Vol. 11, No. 3, pp.5-15.

Shin, B., Higa, K. and Liu Sheng, O. (1997) 'An adoption model of telework for organizations', in Proceedings of the Thirtieth Annual Hawaii International Conference of System Sciences, pp.110-119.

Standen, P. (2000) 'Organisational culture and telework', in Daniels, K., Lamond, D.A. and Standen, P. (Eds.): Managing Telework. Perspectives from Human Resource Management and Work Psychology, pp.31-42, Thomas Learning, London.

Taskin, L. and Bridoux, F. (2010) 'Telework: a challenge to knowledge transfer in organizations', The International Journal of Human Resource Management, Vol. 21, No. 13, pp.2503-2520.

Taskin, L. and Edwards, P. (2007) 'The possibilities and limits of telework in a bureaucratic environment: lessons from the public sector', New Technology, Work and Employment, Vol. 22, No. 3, pp.195-207.

Van Klaveren, M., Tijdens, K., Peters, P. and Wetzels, C. (2005) 'IT and telework', in Peper, B., Doorne-Huiskes, A. and Den Dulk, L. (Eds.): Flexible Working and Organisational Change. The Integration of Work and Personal Life, pp.268-97, Edward Elgar, Cheltenham.

Yap, C.S. and Tng, H. (1990) 'Factors associated with attitudes towards telecommuting', Information and Management, Vol. 19, No. 4, pp.227-35. 